\title{
LXR Agonist Regulates the Carcinogenesis of PCa via the SOCS3 Pathway
}

\author{
Weihua Fu Jiwei Yao Yan Huang ${ }^{\mathrm{b}}$ Qianwei Lia Weibing $\mathrm{Li}^{\mathrm{a}}$ Zhiwen Chen \\ Fengtian $\mathrm{He}^{\mathrm{c}}$ Zhansong Zhou ${ }^{\mathrm{a}}$ Junan Yan ${ }^{\mathrm{a}}$ \\ aDepartment of Urology, Southwest Hospital, Third Military Medical University, Chongqing, \\ bDepartment of Oncology, Xinqiao Hospital, Third Military Medical University, Chongqing, \\ 'Department of Biochemistry and Molecular Biology, College of Basic Medical Sciences, \\ Third Military Medical University, Chongqing, China
}

\section{Key Words}

Suppressor of cytokine signaling $3 \cdot$ Liver $X$ receptors $\cdot$ Small-interfering RNA $\cdot$ Tumorgenesis - Prostate cancer

\begin{abstract}
Background: Down-regulation of suppressor of cytokine signaling 3 (SOCS3) inhibits prostate cancer ( $\mathrm{PCa}$ ) cell growth. Liver $\mathrm{X}$ receptors (LXRs) agonists have been recently introduced for PCa treatment. We postulated that LXR may inhibit the carcinogenesis of PCa via the SOCS3 pathway. Methods: LNCaP cells were cultured and transfected with SOCS3 small-interfering RNA (SOCS3-siRNA) and control small-interfering RNA (control-siRNA). Then cells were treated with LXR activator (GW3965). The expressions of PCa related transcript factors, e.g. transcription 3 (STAT3), nuclear factor kappa B (NF-KB) and activation protein 1(AP1) were detected by western blot assay. In vitro cell proliferation, cell migration, cell invasion and apoptosis were analysed. Nude mice were used for in vivo tumorgenesis. Results: In cells treated with control-siRNA, GW3965 enhanced SOCS3 expression and significantly inhibited the phosphorylation of STAT3, NF-KB and AP1 expressions, accompanied by dramatically reduced cellular proliferation rate, immigration and invasion of cultured cells. In cells treated with SOCS3-siRNA, the inhibitory effects of LXR activator on the phosphorylation of STAT3 and expressions of NF-KB and AP1 were totally abolished. The cell proliferation rate, immigration and invasion were markedly elevated by SOCS3 gene mutation, even with GW3965 treatment. The in vivo tumorgenesis assay showed that GW3965 significantly reduced the tumor volumes in tumor-bearing nude mice receiving saline injection, but failed to limit the tumor volume in tumor-bearing nude mice receiving SOCS3 antibody injection. Conclusion: Our results provide evidence in support of the notion that LXR agonist may regulate the carcinogenesis of PCa via the SOCS3 pathway.
\end{abstract}


Fu et al.: LXR/SOCS3 Pathway in PCa

\section{Introduction}

Prostate cancer (PCa) is the second most frequently diagnosed cancer and the sixth leading cause of cancer deaths in males [1-3]. The molecular events responsible for initiation and progression of PCa remain poorly understood [4]. Several epidemiological studies showed that chronic inflammation plays an important role in prostate carcinogenesis [57]. The suppressor of cytokine signaling 3 (SOCS3) is one of the most important inhibitory molecule of inflammatory signal transduction pathways [8, 9]. SOCS3 suppressor is upregulated by androgen in prostate cancer cell lines, where it inhibits androgen-mediated proliferation and secretion [10]. Down-regulation of SOCS3 causes cell death of prostate cancer through activation of the extrinsic and intrinsic apoptosis pathways [11]. The underlying mechanism is that SOCS3 antagonizes the proliferative and migratory ability in prostate cancer by inhibition of p44/p42 MAPK signaling [12]. In addition, SOCS3 inhibit the signal transducer and activator closely related to Pca cell proliferation and invasiveness, such as transcription 3 (STAT3) [13-15], nuclear factor kappa B (NF- $\mathrm{B}$ ) [16] and activation protein 1(AP1) [17].

Recently, a few new agents have been introduced for PCa treatment, one of which is the liver X receptors (LXRs) agonist. LXRs have been shown to be the important regulators of cholesterol, fatty acid, immunity and glucose homeostasis [18, 19]. LXR agonists suppress proliferation of multiple human cancer cell lines in vitro as well as suppress the growth and progression of prostate tumor xenografts in nude mice. Treatment with the synthetic LXR agonist down-regulated the Akt survival pathway and thus induced apoptosis of LNCaP cells in both xenografted nude mice and cell culture [20]. Targeting the transcriptional activity of LXRs has, therefore, been proposed as a mechanism for attenuating the progression of prostate cancer $[21,22]$.

SOCS3 is an inducible cytokine and its expression is regulated by a variety of nuclear receptor, such as peroxisome-proliferator-activated receptor $\alpha$ (PPAR) $\beta / \delta$. LXR is also a nuclear receptor that controls the expression of genes involved in glucose and lipid homoeostasis. Previous study suggests that PPAR $\alpha$-LXR is a novel metabolite coupling signal axis in skeletal muscle that acts to optimize substrate selection in response to nutrient status. Based on the above mentioned studies, we postulated that LXR may regulate the carcinogenesis of PCa via the SOCS3 pathway. In the present study, we explored the hypothesis using cultured cell line and nude mice.

\section{Materials and Methods}

\section{Cell culture and treatment}

Three PCa cell lines, namely, LNCaP, DU145 and PC-3 were cultured in RPMI-1640 supplemented with 10\% fetal calf serum (FCS), $50 \mathrm{U} / \mathrm{mL}$ Penicillin G, and $50 \mu \mathrm{g} / \mathrm{mL}$ Streptomycin (Invitrogen, Carlsbad, CA). Trypsin was used for cell passage.

\section{Small-interfering RNA transfection}

Cells were seeded into 6-well plates and were grown until $>75 \%$ confluent. The cells were transiently transfected with $25 \mathrm{nmol} / \mathrm{L}$ of SOCS3 small-interfering RNA (SOCS3-siRNA) or negative control siRNA (control-siRNA) (Dharmacon (Lafayette, CO, United States) using Dharma FECT 4 transfection reagents according to the manufacturer's instructions. After $24 \mathrm{~h}$, fluorescent images of transfected cells were observed under fluorescence microscope (Nikon, Japan). Transfection rates of $70 \%-80 \%$ of the cells were accepted for all the experiments [23]. The protein expression of SOCS3 was detected by Western blotting.

Cell treatment

Cells transfected with SOCS3-siRNA and control-siRNA were treated with LXR activator (GW3965, 20uM for 2 hours, Invitrogen, Carlsbad, CA). Cells without GW3965 treatment were used as controls. 
Fu et al.: LXR/SOCS3 Pathway in PCa

Western Blot Analysis

Cells were collected and lysed in lyses buffer. The protein contents were determined. Samples were resolved by SDS-PAGE and electroblotted onto a polyvinylidene difluoride membrane. Afterward, membranes were incubated respectively with an anti-SOCS3 monoclonal antibody (1:1000 dilution, Life Technologies, USA), anti-LXR Polyclonal antibodies (1:1000 dilution, Novus Biologicals,USA), antiphosphorylated STAT3 monoclonal antibody (p-STAT3, 1:1000 dilution, Life Technologies, USA) and total STAT3 monoclonal antibody (t-STAT3, 1:1000 dilution, Life Technologies, USA), anti-AP1 polyclonal antibody (1:1000 dilution, Santa Cruz Biotechnology,USA), anti-NF- $\kappa B$ polyclonal antibody (1:1000 dilution, Biovision, USA) and anti-glyceraldehyde-3-phosphate dehydrogenase (as reference, anti-GAPDH, 1:1000 dilution, Santa Cruz Biotechnology,USA) antibody overnight at $4^{\circ} \mathrm{C}$, followed by incubation with the horseradish peroxidase-conjugated anti-rabbit IgG for $1 \mathrm{~h}$ at room temperature. The signals were enhanced using a chemiluminescence system. The detection for each protein was repeated three times.

\section{Cell Proliferation Assay}

MTT assay was performed according to manufacturer instructions (Sigma Aldrich). Briefly, cells were washed in PBS. MTT reagent (3-(4, 5-dimethylthiazol-2-yl)-2, 5-diphenyltetrazolium bromide, M 2128, Sigma Aldrich) was added and incubated at $37^{\circ} \mathrm{C}$ for $3 \mathrm{hrs}$. After MTT reagent removal, MTT solvent (10 $\%$ Triton 100X and 0.1 N HCL in anhydrous isopropanol) was added. Absorbance was determined in a Microwell plate reader (Model 680, Biorad, Marnes-La-Coquette, France).

\section{Terminal Deoxynucleotidyl Transferase dUTP Nick End Labeling (TUNEL) Assay}

The apoptosis in the cultured cell lines were detected by in situ DeadEndTM Colorimetric Apoptosis Detection System (Promega, Madison, WI) according to the manufacturer's instructions. Briefly, cells were incubated with terminal deoxynucleotidyl transferase enzyme in a humidified chamber at $37{ }^{\circ} \mathrm{C}$ for $60 \mathrm{~min}$. The reaction was terminated by transferring the slides to $2 \times$ sodium citrate saline solution. The sections were counter stained with DAPI. For quantitative analyses, 5 fields per section were selected. Apoptosis was indexed by counting TUNEL positive cells per 100 nuclei per section.

\section{Cell Migration and Invasion Assay}

For migration assay, $1 \times 10^{5}$ cells were seeded on the upper compartment of 24-well Transwell culture chamber. After $24 \mathrm{~h}$ incubation, non-traversed cells were removed from the upper surface of the filter carefully with a cotton swab. Traversed cells on the lower side of the filter were stained with crystal violet and counted.

The invasion assay was performed using a modified two-chamber plates. $30 \mu \mathrm{lof} 50 \mathrm{mg} / \mathrm{ml}$ Matrigel (BD Biosciences, Mississauga, Canada) in serum-free medium was added to the upper compartment of 24well Transwell culture chamber. $1 \times 10^{5}$ cells suspended in $200 \mu \mathrm{l}$ of serum-free medium were seeded on the upper compartment, and $600 \mu \mathrm{l}$ of complete medium was added to the lower compartment. After $24 \mathrm{~h}$ incubation at $37^{\circ} \mathrm{C}$, cells were fixed with methanol. Non-invaded cells were removed from the upper surface of the filter carefully with a cotton swab. Invaded cells on the lower side of the filter were stained with crystal violet and counted.

\section{In vivo tumorgenesis assay}

For in vivo tumorgenesis assay, nude mice were inoculated subcutaneously with LNCaP cells $\left(1 \times 10^{6}\right)$ animal). The mice were raised to allow in vivo tumorgenesis. Two weeks later, selecting mice which had tumors with similar size (about $100 \mathrm{~mm}^{3}$ ) for the tumor growth inhibition studies. The selected tumorbearing mice were injected with the anti-SOCS3 antibody (dose: $5 \mathrm{ug} / \mathrm{g}$ for 7 days) and the same volume of saline via vein tail. Then mice were divided into four groups, namely, saline injection, saline injection+ GW3965, anti-SOCS3 antibody injection and anti-SOCS3 + GW3965 groups (each group, n=6). GW3965 was given by an oral gavage administration method ( $40 \mathrm{mg} / \mathrm{kg}$ daily for 14 days). Mice were sacrificed after 7 days $(n=3)$ and after 14 days $(n=3)$. Tumor volumes were calculated using the following formula: (cubic millimeters $)=($ length $\times$ width $) \times 0.5$. 


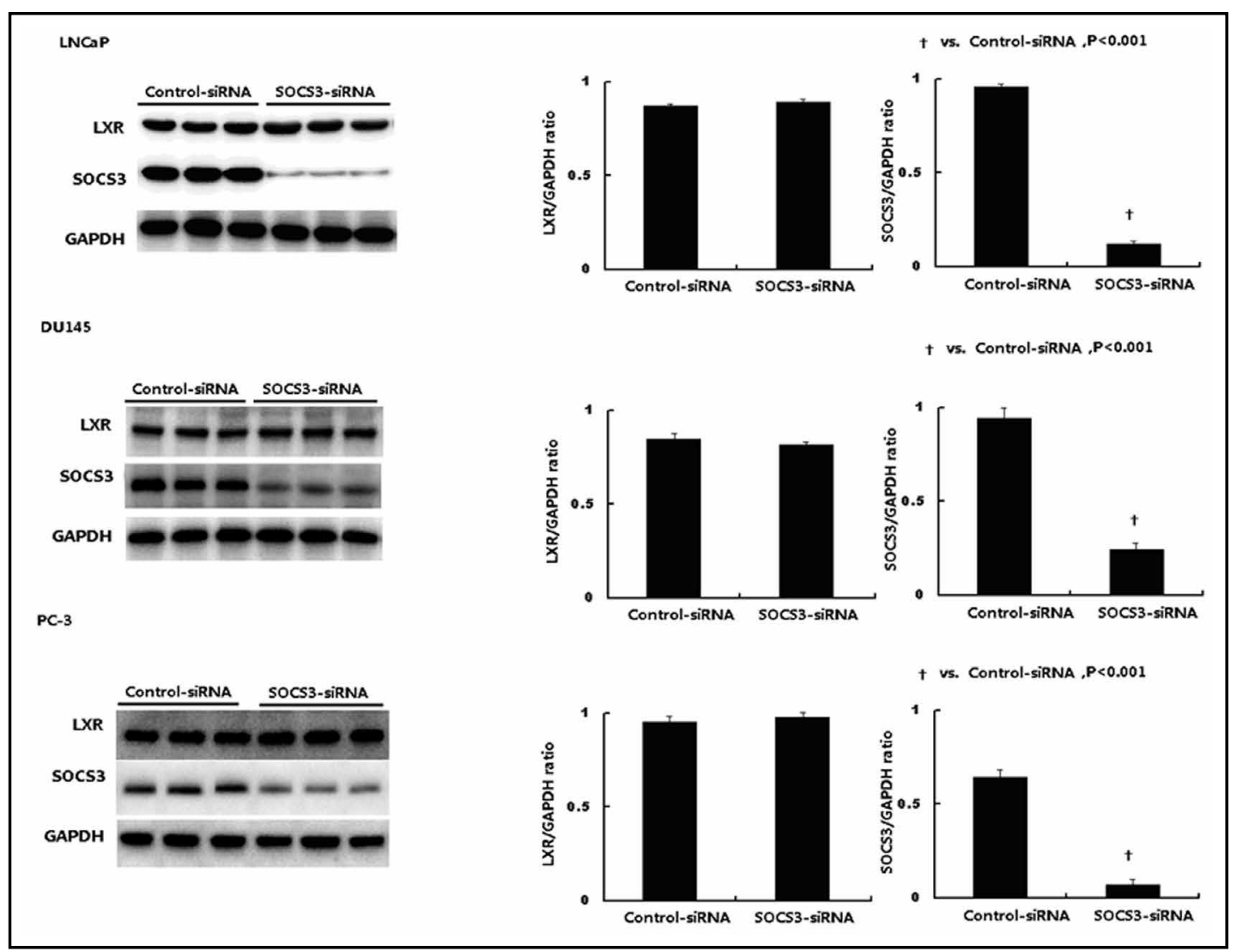

Fig. 1. Western blot assay showed that the SOCS3-siRNA transfection significantly reduced the SOCS3 expression in all three Pca cell lines, namely, LNCaP, DU145 and PC-3, compared to control-siRNA transfection. The LXR expression levels were not affected by SOCS3-siRNA transfection in these cell lines.

\section{Statistical Analysis}

To evaluate the amount of protein expression, the Raytest TINA software (http://www.raytest.de/ service/raytest_catalog.html) was used for western blotting to calculate the densitometric analysis as described previously [24]. The differences in the relative expressions among different genotypes were compared by using ANOVA analyses. The analyses were performed with the SPSS software (Statistical Package for the Social Sciences, version 16.0, SPSS Inc, Chicago, IL, USA).

\section{Results}

Si-RNA transfection significantly reduced the SOCS3 expression

The protein expression of SOCS3 after si-RNA transfection was detected by Western blotting. Compared to cell transfected with control-siRNA, all the cell lines transfected with SOCS3-siRNA had significantly reduced SOCS3 expression; however, the inhibition of SOCS3 did not affect the LXR expression in these cell lines (Fig. 1).

The effects of LXR activator on SOCS3 expressions in PCa cell lines treated with SOCS3SiRNA and control-siRNA

Cell lines transfected with control-siRNA or SOCS3-siRNA were treated with or without LXR activator GW3965, respectively. Compared to untreated cells, the application of GW3965 dramatically increased the LXR expression in both cells treated with control-siRNA and SOCS3-siRNA (Fig. 2). In all cell lines treated with control-siRNA, the LXR activator induced significantly enhanced SOCS3 expressions, accompanied with significantly reduced 


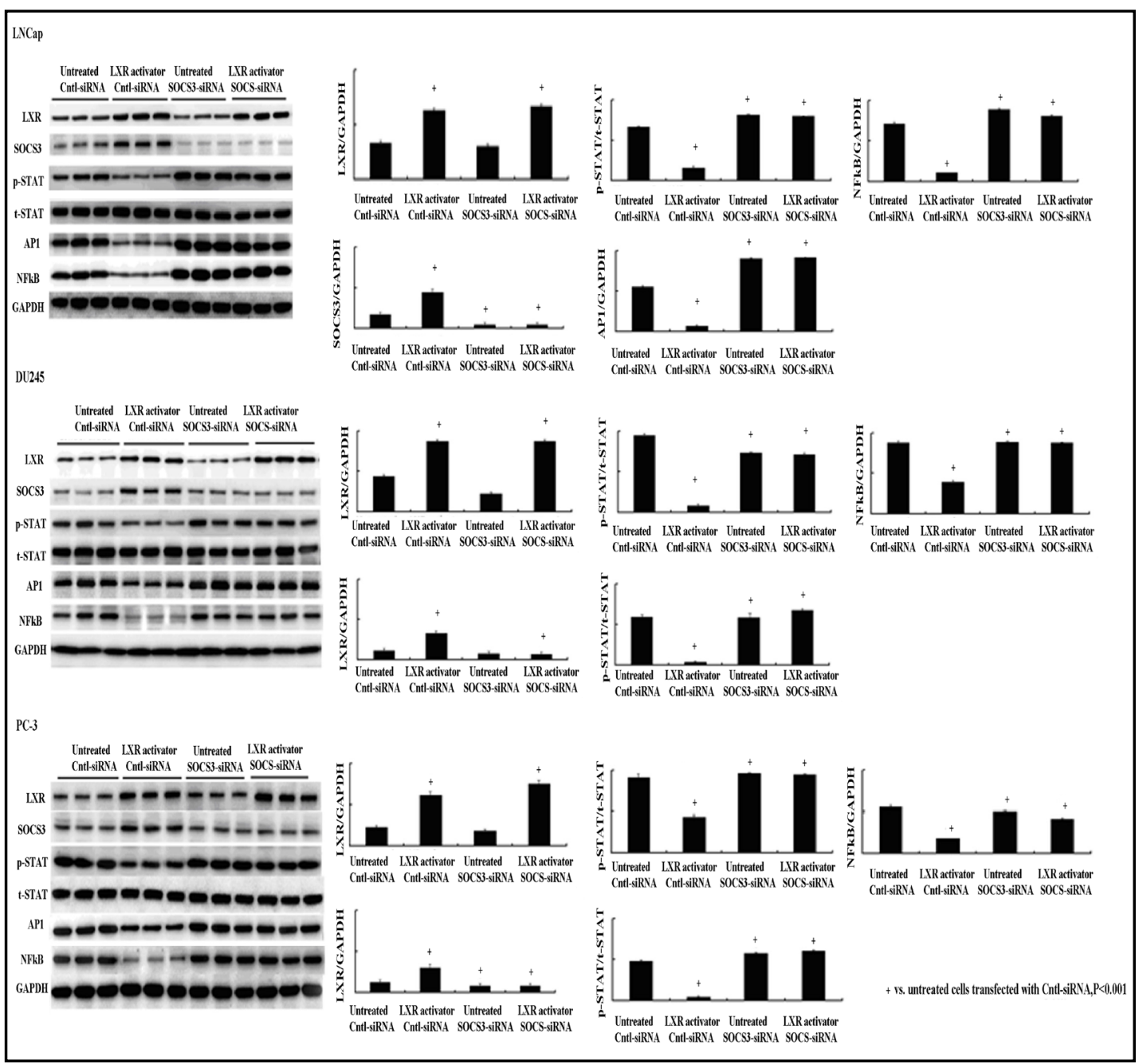

Fig. 2. LXR activator GW3965 dramatically increased the LXR expression in LNCaP, DU145 and PC-3 cell lines. Quantitative analyses showed that GW3965 enhanced the expressions of SOCS3, p-STAT, NF- $\mathrm{kB}$ and AP1 only in cells treated with control-siRNA, but in cells transfected with SOCS3 si-RNA, all these inhibitory effects were totally abolished.

phosphorylated STAT3 levels, NFkB and AP1 expressions, compared to cell lines without GW3965 treatment. Nevertheless, in cell lines treated with SOCS3-siRNA, the inhibitory effects of LXR activator on the phosphorylation levels of STAT3 and expressions of NF- $\mathrm{B}$ and AP1 were totally abolished (Fig. 2).

The biological behaviors of PCa cell lines with or without LXR activator treatment

In cell lines transfected with control-siRNA, the administration of LXR activator significantly reduced cellular proliferation rate, reduced immigration and invasion (vs. untreated cells, all P<0.001 in LNCaP, DU145 and PC-3 cell lines, Fig. 3). The apoptosis rates were all significantly increased in LNCaP, DU145 and PC-3 cell lines treated with GW3965 than untreated cells (all P<0.001, Fig. 3). In contrast, in cells treated with SOCS3-siRNA, the proliferation rate, immigration and invasiveness abilities of LNCaP, DU145 and PC-3 cell lines at baseline level were significantly higher, but the apoptosis rates were dramatically lower than cell lines transfected with control-siRNA (all $\mathrm{P}<0.001$ ). In these cell lines treated with SOCS3-siRNA, the addition of LXR activator did not change the cell proliferation, immigration and invasiveness abilities as well as apoptosis rates (vs. untreated cells receiving controlsiRNA transfecteion, all $\mathrm{P}<0.001$, Fig. 3). 


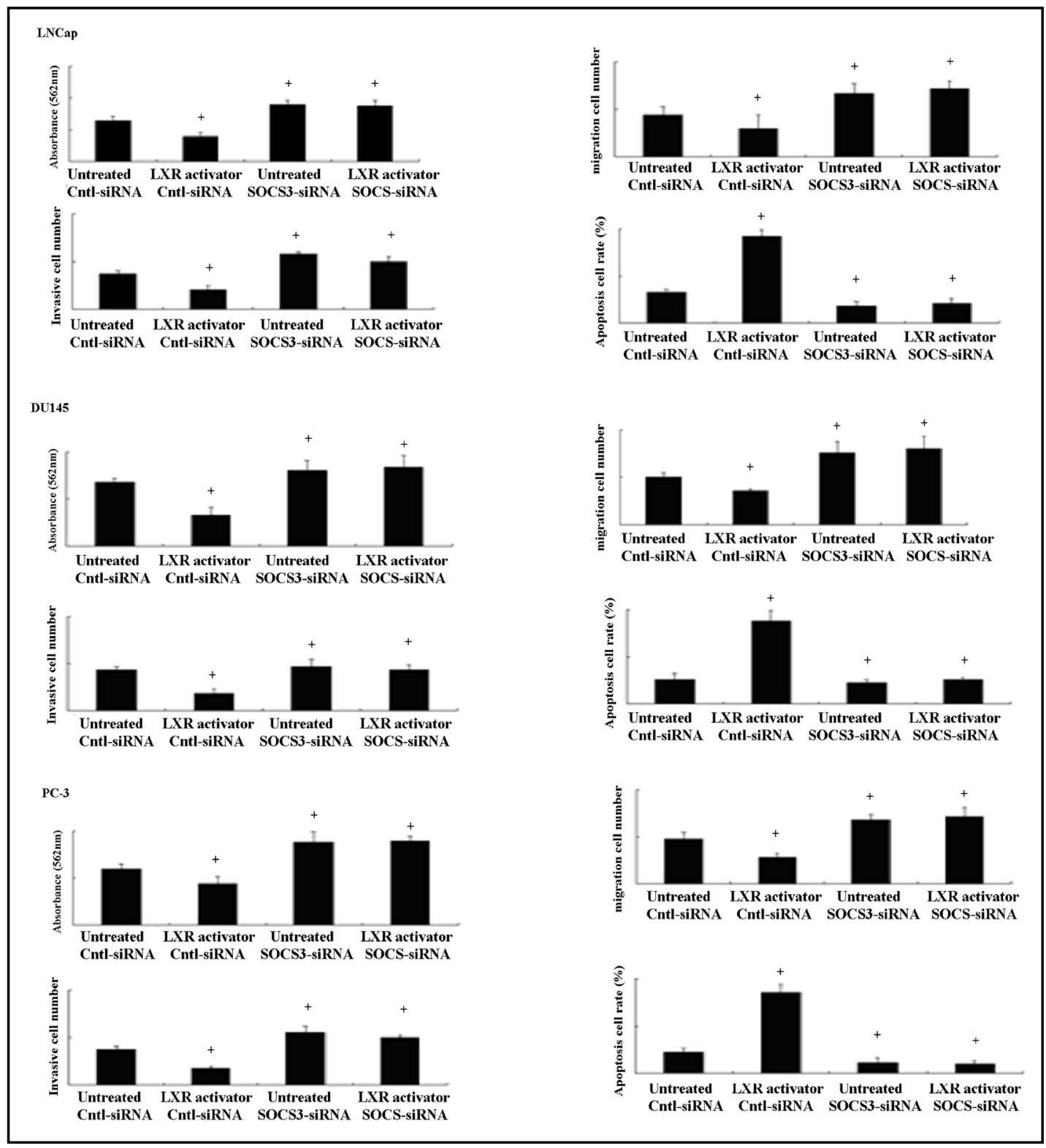

Fig. 3. In cells transfected with control-siRNA, LXR activator GW3965 significantly reduced cellular proliferation rate, immigration and invasion abilities and increased PCa cell apoptosis. However, in in cells transfected with SOCS3-siRNA, LXR activator failed to change the cell proliferation, immigration and invasiveness abilities as well as apoptosis rate.

\section{In vivo tumorgenesis}

The size of tumors in mice receiving saline injection, anti-SOCS3 antibody injection and anti-SOCS3 antibody+ GW3965 increased dramatically at day 7 and day 14, however, that in mice receiving saline + GW3965 treatment was significantly decreased. At day 7, the tumor volume was $254 \pm 23 \mathrm{~mm}^{3}$ in mice receiving saline injection, $122 \pm 21 \mathrm{~mm}^{3}$ in mice receiving saline + GW3965, 302 $\pm 19 \mathrm{~mm}^{3}$ in anti-SOCS3 antibody treated mice and $278 \pm 20 \mathrm{~mm}^{3}$ in antiSOCS3 antibody+ GW3965 treated mice $(\mathrm{P}<0.001)$. At day 14 , the tumor volume was $567 \pm 38$ $\mathrm{mm}^{3}$ in mice receiving saline injection, $195 \pm 42 \mathrm{~mm}^{3}$ in mice receiving saline + GW3965, $529 \pm 50 \mathrm{~mm}^{3}$ in anti-SOCS3 antibody treated mice and $538 \pm 47 \mathrm{~mm}^{3}$ in anti-SOCS3 antibody+ GW3965 treated mice $(\mathrm{P}<0.001)$. 


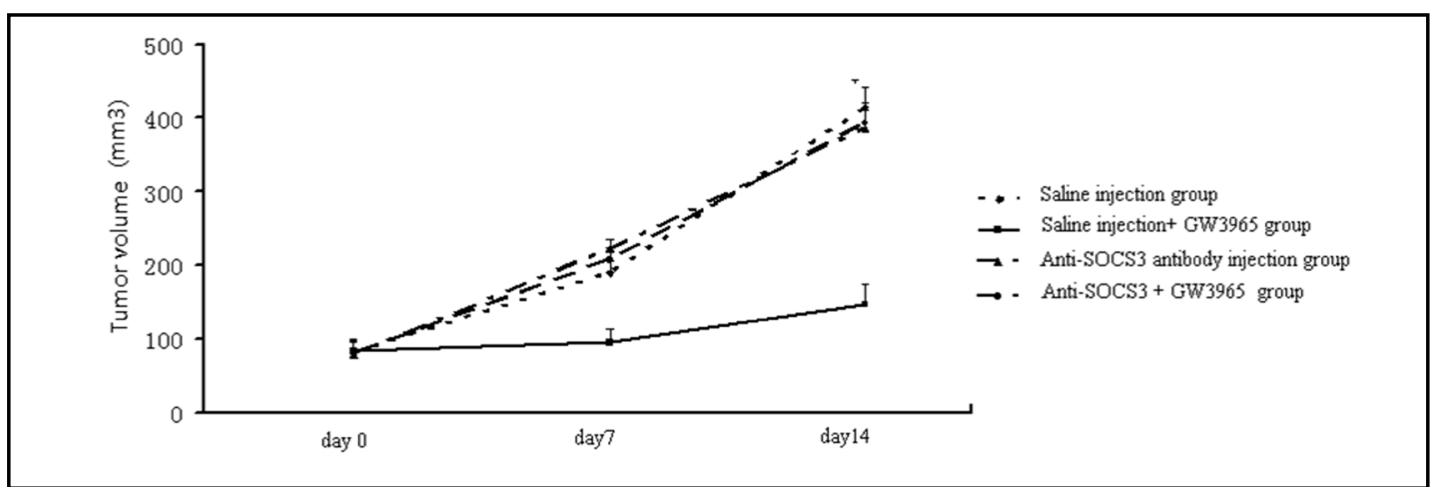

Fig. 4. GW3965 treatment significantly inhibited tumor growth in tumor-bearing mice receiving saline injection, but failed to do so in tumor-bearing mice receiving anti-SOCS3 antibody injection. At day 7, the tumor volume was $254 \pm 23 \mathrm{~mm}^{3}$ in mice receiving saline injection, $122 \pm 21 \mathrm{~mm}^{3}$ in mice receiving saline + GW3965, 302 $\pm 19 \mathrm{~mm}^{3}$ in anti-SOCS3 antibody treated mice and $278 \pm 20 \mathrm{~mm}^{3}$ in anti-SOCS3 antibody+ GW3965 treated mice $(\mathrm{P}<0.001)$. At day 14 , the tumor volume was $567 \pm 38 \mathrm{~mm}^{3}$ in mice receiving saline injection, $195 \pm 42 \mathrm{~mm}^{3}$ in mice receiving saline $+\mathrm{GW} 3965,529 \pm 50 \mathrm{~mm}^{3}$ in anti-SOCS3 antibody treated mice and $538 \pm 47 \mathrm{~mm}^{3}$ in anti-SOCS3 antibody+ GW3965 treated mice $(\mathrm{P}<0.001)$. $\dagger$ comparison at day7, $\mathrm{P}<0.001 ; \neq$ comparison at day $14, \mathrm{P}<0.001$

\section{Discussion}

In this study, we observed that treatment of the LXR activator (GW3965) and control siRNA induced elevated expression of SOCS3, and conversely reduced expression of phosphorylated STAT3, NF- $\mathrm{KB}$ and AP1 in the LNCaP cells. The association of transcription factors, i.e. STAT3, NF- $\kappa$ B and AP1, in promoting metastatic progression of prostate cancer has been previously demonstrated [25-27]. From our study, this decreased expression of the transcription factors also correlates with depressed progression of the PCa cells in vitro indicated by significantly reduced proliferation, immigration and invasion of tumor cells, in addition to a longer period to develop prostate cancer in the tumor-bearing nude mice compared to the controls. Interestingly, the effects of GW3965 on both SOCS3 and the transcription factors, STAT3, NF- $\mathrm{\kappa B}$ and AP1, were noted to be abolished upon treatment of SOCS3-siRNA in the LNCaP cells in vitro. Furthermore, the treatment of the SOCS3 antibody and GW3965 was associated with the significantly larger mean tumor size in the nude mice compared to mice treated with GW3965 alone. These findings suggest the potential role of the LXR activator in conferring protection against PCa cells possibly through SOCS3.

LXRs play a key role in cross-talking between lipogenesis and inflammation [28]. Growing evidence has shown that both chronic inflammation and lipids may contribute to the development of PCa [21, 29]. The involvement of LXRs in carcinogenesis of PCa has been widely studied and reported [8,30-32]. Given the extensive involvement of SOCS3 in the LXR signaling pathway [28, 33, 34], and its own correlation with the survival of PCa patients [35], we seek further understanding of the association of SOCS3 in the function of LXRs, and its role in development of $\mathrm{PCa}$.

Like LXRs, SOCS3 also acts as a molecular link between lipid metabolism and inflammation [22]. SOCS3, the adapter-encoding gene, is a critical transcriptional target of PPAR $\gamma$. LXRs induce the expression of lipogenic genes, including PPAR $\gamma[28,36]$, and, thereby, enhanced expression of SOCS3. On the other hand, LXRs down-regulate the expression of inflammatory genes, such as TNF $\alpha$ and IL-6 $[28,36]$, and the latter potently induces SOCS3 that, in turn, terminates IL-6 signal transduction through a feedback loop [28]. In addition, promoter binding of SOCS3 with PPAR $\gamma$ represses differentiation of proinflammatory cells, such as the T-helper (TH) 17 cells [33]. Therefore, SOCS3 mediate the function of LXRs involving in both 
Fu et al.: LXR/SOCS3 Pathway in PCa

inhibiting the inflammatory response and promoting lipid metabolism [30], which conveys protection against $\mathrm{PCa}$ cells and facilitates $\mathrm{PCa}$ progression, respectively.

Because of the paradoxical roles of LXRs, conflicting reports exist regarding to their effects on the development of PCa. For example, the LXRs agonist has been indicated to both facilitate [21] and attenuate [20] progression of PCa because of their function in enhancing lipid metabolism and reducing inflammatory response. Although our study agrees with the latter finding, a similarly controlled microenvironment, such as studied cells, animals, treatment dosages and compounds, should be approached in order to reach comparable results. In our study, we utilized the LNCaP cell line that is characterized by a reduced amount of cells in the $S$ phase, regulation of which has been considered involved in enhanced cholesterol efflux via LXR-induced expression of the cholesterol transporter-ABCA1. A recent report has shown that treatment of the LXR activator may result in lowering of cellular cholesterol led by accumulation of ABCA1, reduction of the lipid raft size, and consequently decrease of the cell survival [22]. It suggests that not only an anti-proliferative effect but also a pro-apoptotic effect in the LNCaP cells may contribute to protection against malignancy of the LNCaP cells with administration of the LXR activator.

Altogether, our study demonstrated a putative role of LXR activation in suppressing PCa tumorigenesis using both the in vivo and in vitro methods. We found that reduced production of phosphorylated STAT3, NF- $\mathrm{KB}$ and AP1 and enhanced SOCS3 expression were accompanied with improved animal survivals and retained aggression of the PCa cells treated with the LXR activator. Blocking the function of SOCS3 via si-RNA in vitro abolished the effects of the LXR activator, resulting in increased production of phosphorylated STAT3, NF- $\kappa \mathrm{B}$ and AP1 accompanied with aggressive malignant progression of the PCa cell line. It currently lacks of understanding on the role of SOCS3 in outcomes of PCa. Our study intends to provide information on an alternative target and potentially a novel treatment option for PCa patients.

\section{Conflict of Interests}

None.

\section{Acknowledgements}

This study was supported by a grant from the Nature Science foundation of Chongqing, China (CSTC2012JJA0409).

\section{References}

1 Shariat SF, Scherr DS, Gupta A, Bianco FJ Jr, Karakiewicz PI, Zeltser IS, Samadi DB, Akhavan A: Emerging biomarkers for prostate cancer diagnosis, staging, and prognosis. Arch Esp Urol 2011;64:681-694.

-2 Albiges-Sauvin L, Levy A, Massard C, Fizazi K: Prognosis and predictive factors in prostate cancer. Bull Cancer 2009;96:439-449.

-3 Drouin SJ, Roupret M: Epidemiology, diagnosis and prognosis of localized prostate cancer: what's new? Prog Urol 2009;19:S3-7.

-4 Tasken KA, Angelsen A, Svindland A, Eide T, Berge V, Wahlquist R, Karlsen S: Markers for diagnosis, prediction and prognosis of prostate cancer. Tidsskr Nor Laegeforen 2005;125:3279-3282.

-5 Donnell RF: Epidemiology of inflammation and prostate cancer. Curr Urol Rep 2004;5:297.

6 Nelson WG, De Marzo AM, DeWeese TL, Isaacs WB: The role of inflammation in the pathogenesis of prostate cancer. J Urol 2004;172:S6-11.

7 Sfanos KS, De Marzo AM: Prostate cancer and inflammation: the evidence. Histopathology 2012;60:199215. 
Fu et al.: LXR/SOCS3 Pathway in PCa

-8 Vegran F, Berger H, Ghiringhelli F, Apetoh L: Socs3 induction by PPARgamma restrains cancer-promoting inflammation. Cell Cycle 2013;2:2157-2158.

-9 White GE, Cotterill A, Addley MR, Soilleux EJ, Greaves DR: Suppressor of cytokine signalling protein SOCS3 expression is increased at sites of acute and chronic inflammation. J Mol Histol 2011;42:137-151.

$\checkmark 10$ Neuwirt H, Puhr M, Cavarretta IT, Mitterberger M, Hobisch A, Culig Z: Suppressor of cytokine signalling-3 is up-regulated by androgen in prostate cancer cell lines and inhibits androgen-mediated proliferation and secretion. Endocr Relat Cancer 2007;14:1007-1019.

-11 Puhr M, Santer FR, Neuwirt H, Susani M, Nemeth JA, Hobisch A, Kenner L, Culig Z: Down-regulation of suppressor of cytokine signaling-3 causes prostate cancer cell death through activation of the extrinsic and intrinsic apoptosis pathways. Cancer Res 2009;69:7375-7384.

12 Puhr M, Santer FR, Neuwirt H, Marcias G, Hobisch A, Culig Z: SOCS-3 antagonises the proliferative and migratory effects of fibroblast growth factor- 2 in prostate cancer by inhibition of $\mathrm{p} 44 / \mathrm{p} 42 \mathrm{MAPK}$ signalling. Endocr Relat Cancer 2010;17:525-538.

13 Yokogami K, Yamashita S, Takeshima H: Hypoxia-induced decreases in SOCS3 increase STAT3 activation and upregulate VEGF gene expression. Brain Tumor Pathol 2013;30:135-143.

14 Yoshimura A, Naka T, Kubo M: SOCS proteins, cytokine signalling and immune regulation. Nat Rev Immunol 2007;7:454-465.

15 Dhar K, Rakesh K, Pankajakshan D, Agrawal DK: SOCS3 promotor hypermethylation and STAT3-NF-kappaB interaction downregulate SOCS3 expression in human coronary artery smooth muscle cells. Am J Physiol Heart Circ Physiol 2013;304:H776-785.

16 Park SH, Kim KE, Hwang HY, Kim TY: Regulatory effect of SOCS on NF-kappaB activity in murine monocytes/macrophages. DNA Cell Biol 2003;22:131-139.

17 Barclay JL, Anderson ST, Waters MJ, Curlewis JD: Regulation of suppressor of cytokine signaling 3 (SOC3) by growth hormone in pro-B cells. Mol Endocrinol 2007;21:2503-2515.

18 Wagner M, Zollner G, Trauner M: Nuclear receptors in liver disease. Hepatology 2011;53:1023-1034.

19 Cermenati G, Brioschi E, Abbiati F, Melcangi RC, Caruso D, Mitro N: Liver X receptors, nervous system, and lipid metabolism. J Endocrinol Invest 2013;36:435-443.

20 Pommier AJ, Alves G, Viennois E, Bernard S, Communal Y, Sion B, Marceau G, Damon C, Mouzat K, Caira F, Baron S, Lobaccaro JM: Liver X Receptor activation downregulates AKT survival signaling in lipid rafts and induces apoptosis of prostate cancer cells. Oncogene 2010;29:2712-2723.

21 Hoang JJ, Baron S, Volle DH, Lobaccaro JM, Trousson A: Lipids, LXRs and prostate cancer: are HDACs a new link? Biochem Pharmacol 2013;86:168-174.

22 Dufour J, Pommier A, Alves G, De Boussac H, Lours-Calet C, Volle DH, Lobaccaro JM, Baron S: Lack of liver $\mathrm{X}$ receptors leads to cell proliferation in a model of mouse dorsal prostate epithelial cell. PLoS One 2013;8:e58876.

23 Ji YY, Wang ZD, Li ZF, Li K: Interference of suppressor of cytokine signaling 3 promotes epithelialmesenchymal transition in MHCC97H cells. World J Gastroenterol 2013;19:866-873.

24 Lee JH, Pyon JK, Lee SH, Lee YJ, Kang SG, Kim CH, Kim DW, Nam HS, Park YH, Jeong DJ, Cho MK: Greater expression of TC21/R-ras2 in highly aggressive malignant skin cancer. Int J Dermatol 2011;50:956-960.

-25 Abdulghani J, Gu L, Dagvadorj A, Lutz J, Leiby B, Bonuccelli G, Lisanti MP, Zellweger T, Alanen K, Mirtti T, Visakorpi T, Bubendorf L, Nevalainen MT: Stat3 Promotes Metastatic Progression of Prostate Cancer. The Am J Pathol 2008;172:1717-1728.

26 Andela VB, Gordon AH, Zotalis G, Rosier RN, Goater JJ, Lewis GD, Schwarz EM, Puzas JE, O'Keefe RJ: NFkappaB: a pivotal transcription factor in prostate cancer metastasis to bone. Clin Orthop Relat Res 2003;415:S75-85.

27 Kajanne R, Miettinen P, Tenhunen M, Leppa S: Transcription factor AP-1 promotes growth and radioresistance in prostate cancer cells. Int J Oncol 2009;35:1175-1182.

28 Lima-Cabello E, Garcia-Mediavilla MV, Miquilena-Colina ME, Vargas-Castrillon J, Lozano-Rodriguez T, Fernandez-Bermejo M, Olcoz JL, Gonzalez-Gallego J, Garcia-Monzon C, Sanchez-Campos S: Enhanced expression of pro-inflammatory mediators and liver X-receptor-regulated lipogenic genes in non-alcoholic fatty liver disease and hepatitis C. Clin Sci (Lond) 2011;120:239-250.

-29 Palapattu GS, Sutcliffe S, Bastian PJ, Platz EA, De Marzo AM, Isaacs WB, Nelson WG: Prostate carcinogenesis and inflammation: emerging insights. Carcinogenesis 2005;26:1170-1181. 
30 Joseph SB, Castrillo A, Laffitte BA, Mangelsdorf DJ, Tontonoz P: Reciprocal regulation of inflammation and lipid metabolism by liver X receptors. Nat Med 2003;9:213-219.

-31 Igci M, Cakmak EA, Oztuzcu S, Bayram A, Arslan A, Gogebakan B, Igci YZ, Cengiz B, Ozkara E, Camci C, Demiryurek AT: Mutational screening of the SOCS3 gene promoter in metastatic colorectal cancer patients. Genet Test Mol Biomarkers 2012;16:1395-1400.

-32 Lin YC, Lin CK, Tsai YH, Weng HH, Li YC, You L, Chen JK, Jablons DM, Yang CT: Adenovirus-mediated SOCS3 gene transfer inhibits the growth and enhances the radiosensitivity of human non-small cell lung cancer cells. Oncol Rep 2010;24:1605-1612.

-33 Berger H, Vegran F, Chikh M, Gilardi F, Ladoire S, Bugaut H, Mignot G, Chalmin F, Bruchard M, Derangere V, Chevriaux A, Rebe C, Ryffel B, Pot C, Hichami A, Desvergne B, Ghiringhelli F, Apetoh L: SOCS3 transactivation by PPARgamma prevents IL-17-driven cancer growth. Cancer Res 2013;73:3578-3590.

-34 Dufour J, Viennois E, De Boussac H, Baron S, Lobaccaro JM: Oxysterol receptors, AKT and prostate cancer. Curr Opin Pharmacol 2012;12:724-728.

35 Reid-Lombardo KM, Fridley BL, Bamlet WR, Cunningham JM, Sarr MG, Petersen GM: Survival is associated with genetic variation in inflammatory pathway genes among patients with resected and unresected pancreatic cancer. Ann Surg 2013;257:1096-1102.

-36 Lo Sasso G, Bovenga F, Murzilli S, Salvatore L, Di Tullio G, Martelli N, D`Orazio A, Rainaldi S, Vacca M, Mangia A, Palasciano G, Moschetta A: Liver X receptors inhibit proliferation of human colorectal cancer cells and growth of intestinal tumors in mice. Gastroenterology 2013;144:1497-1507, 1507 e1-13. 